\title{
Complete Congenital Third Branchial Fistula: A Rare Case Report
}

\author{
${ }^{1}$ Sujata A Gawai, ${ }^{2}$ Kalpana R Kumar, ${ }^{3}$ Vaishali S Sangole, ${ }^{4}$ Suman P Rao \\ ${ }^{5}$ Divya A George, ${ }^{5}$ Rachna Tiwari, ${ }^{6}$ B hagirath D Kandhare \\ ${ }^{1}$ Senior Resident, Department of ENT, MGM Medical College and Hospital, Kamothe, Navi Mumbai, Maharashtra, India \\ ${ }^{2}$ Professor, Department of ENT, MGM Medical College and Hospital, Kamothe, Navi Mumbai, Maharashtra, India \\ ${ }^{3}$ Lecturer, Department of ENT, MGM Medical College and Hospital, Kamothe, Navi Mumbai, Maharashtra, India \\ ${ }^{4}$ Professor and Head, Department of ENT, MGM Medical College and Hospital, Kamothe, Navi Mumbai, Maharashtra, India \\ ${ }^{5}$ Resident, Department of ENT, MGM Medical College and Hospital, Kamothe, Navi Mumbai, Maharashtra, India \\ ${ }^{6}$ Assistant Professor, Department of Radiology, MGM Medical College and Hospital, Kamothe, Navi Mumbai, Maharashtra, India
}

Correspondence: Sujata A G awai, Senior Resident, Department of ENT, MGM Medical College and Hospital, Sector 18, Kamothe Navi Mumbai-410209, Maharashtra, India, Phone: +919987361256, e-mail: drsujatagawai@ gmail.com

\section{ABSTRACT}

Fistulae arising from the second branchial apparatus are the most common anomalies than those arising from the third and fourth branchial apparatus. Third branchial fistula is extremely rare in occurrence. ${ }^{1}$ Complete fistulae are uncommon as in the majority of cases the tracts end blindly. Here, we report a case of complete congenital third branchial fistula on left side of the neck with an internal opening near left pyriform fossa in a 12-year-old male patient.

Keywords: Branchial cleft, Fistula.

\section{INTRODUCTION}

M orethan $90 \%$ of branchial cleftanomaliesarisefrom second branchial cleft system and $8 \%$ from the first branchial cleft system. A nomalies arising from third and fourth branchial cleft system rarely occur. ${ }^{2}$ Persistence of remnants of the branchial apparatus gives riseto a number of w ell-recognized congenital anomalies in the head and neck. A persistent cleft will give rise to an external sinus, a blind ending opening onto the skin. A persistent pouch will cause an internal sinus typically opening into the pharynx, whereas persistence of both cleft and pouch will cause a fistula with an internal and external opening. ${ }^{3}$ Even if an internal opening exists, there lies athin mesodermal tissuebetween theexternal and internal opening. A completebranchial fistula devel ops from a rupture of membrane between the cleft and pouch at the same time during development. ${ }^{4}$ T reatment requires complete excision of the tract in order to prevent recurrence.

\section{CASE REPORT}

A 12-year-old male patient presented to ENT OPD of M GM hospital with history of discharge from the left side of neck since the age of 4 months. He had a history of swelling in the left side of neck at 4 months of age which bursted spontaneously with mucoid discharge through a small opening at the same site. Ever since then there was watery discharge from the opening while drinking.

Examination revealed a small pinpoint opening in the left side of the neck over the anterior border of left sternocleidomastoid muscle, $2 \mathrm{~cm}$ above the medial end of left clavicle (Fig. 1A). Surrounding the opening there was a

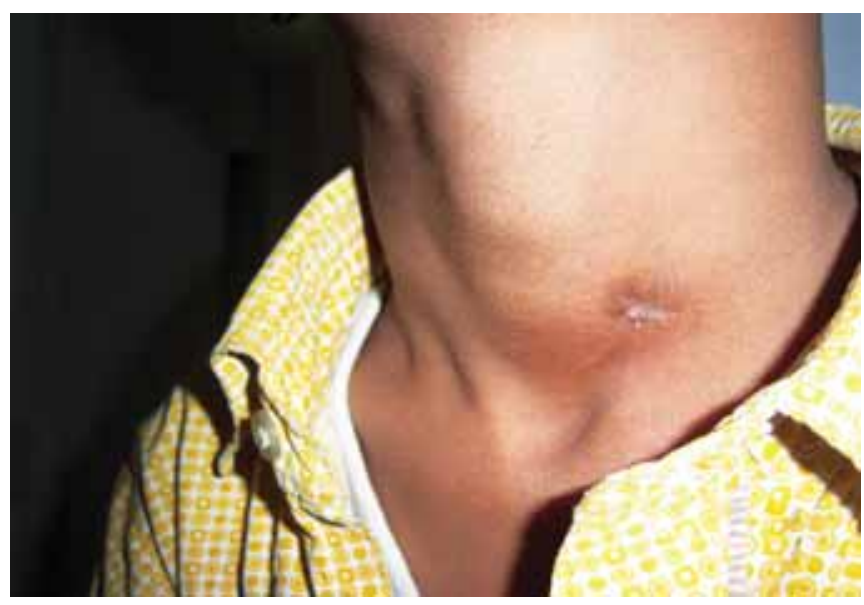

Fig. 1A: External opening of the branchial fistula at the anterior border of left sternocleidomastoid muscle, $2 \mathrm{~cm}$ above medial end of left clavicle

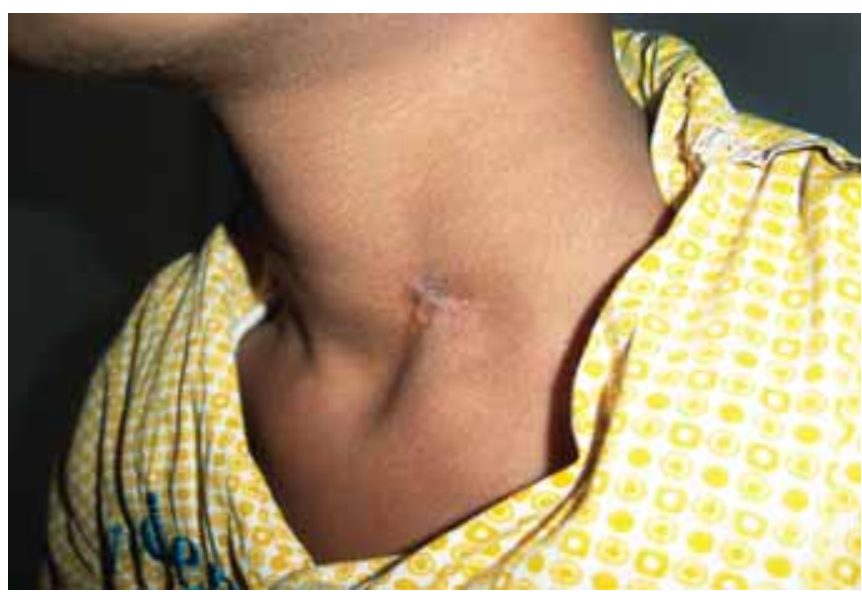

Fig. 1B: Watery discharge seen after giving sip of water to drink 
hyperpigmented area with an old healed scar. Watery discharge was seen after giving a sip of water to the patient for drinking (Fig. 1B).

General examination was within normal limits.

$X$-ray barium swallow was performed to know the site of internal opening but it failed to show any tract. $X$-ray fistulogram was done by cannulating the opening and by injecting diatrizoate meglumine and diatrizoate sodium $76 \%$ after diluting, a fistulous tract was revealed extending superomedially to open in the left side of hypopharynx (Fig. 2).

M RI was performed to know the course of the tract and the site of internal opening, which showed a fistulous communication of the cutaneous opening with left pyriform fossa (Figs $3 \mathrm{~A}$ and $\mathrm{B}$ ). The track was found anterosuperomedial to the left carotid sheath.

For exploration and excision of the fistula, patient was taken under general anesthesia, the external opening was canulated with 24 number angiocatheter, and methylene blue dye was injected which spilled into the pyriform sinus and

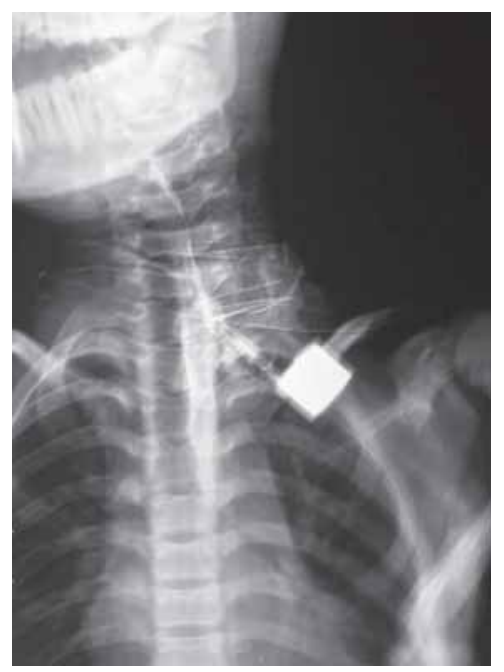

Fig. 2: X-ray fistulogram of branchial fistula

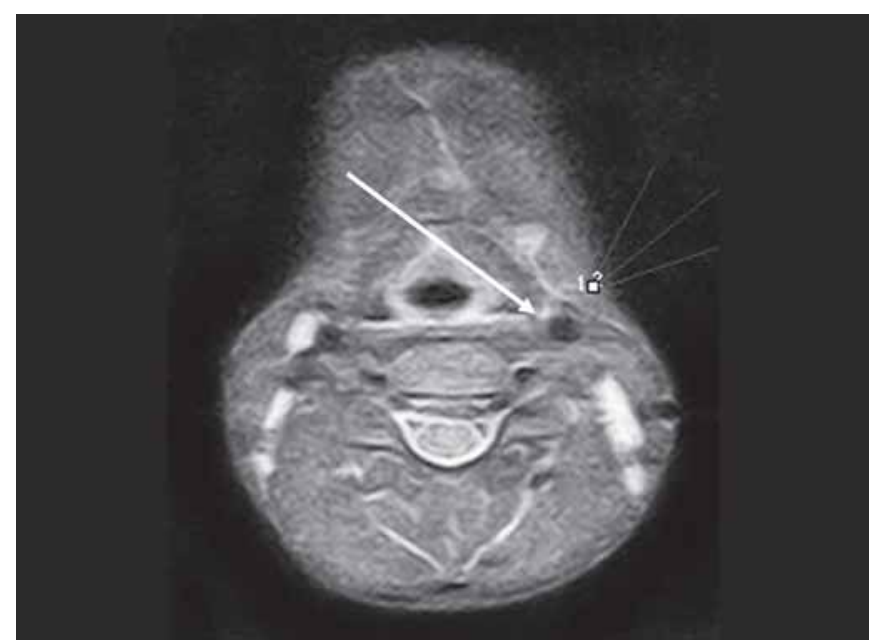

Fig. 3A: MRI of neck shows tract running anterosuperomedial to the left carotid sheath

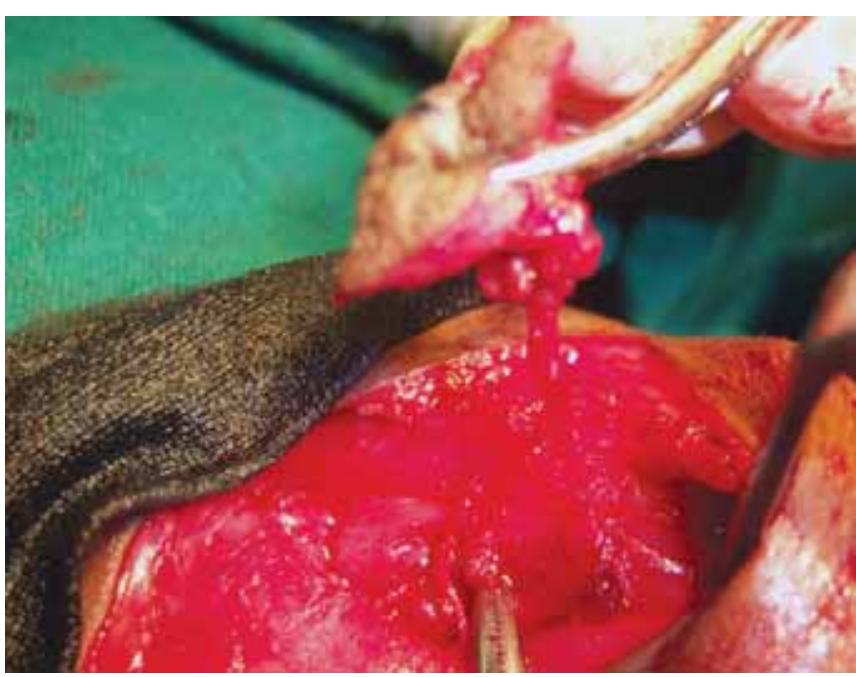

Fig. 4: Intraoperative picture of branchial fistula being excised

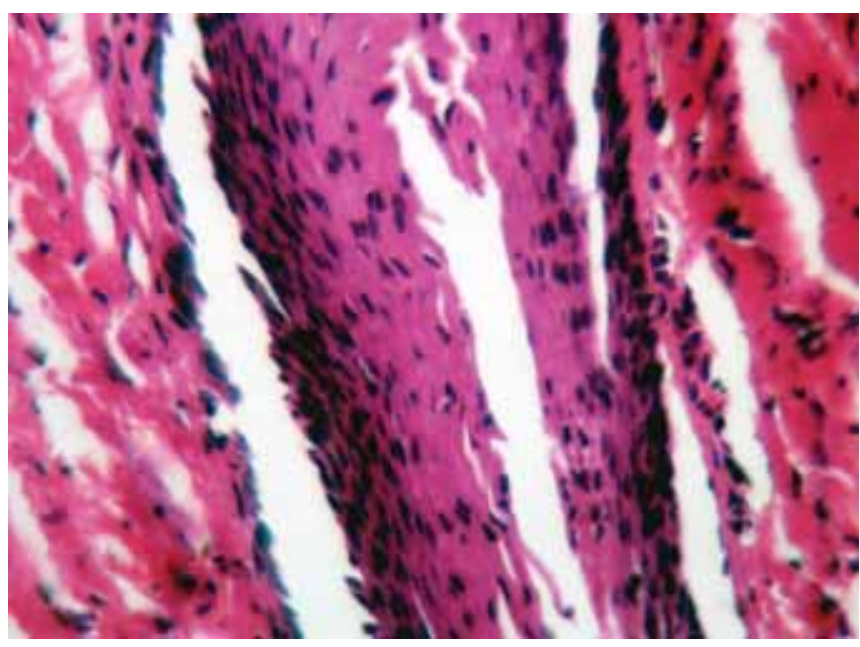

Fig. 5: Histopathological picture showing tract lined by keratinized stratified squamous epithelium

revealed the internal opening on direct laryngoscopy. A transverse elliptical incision was made around the external opening and subplatysmal flaps were raised carefully, the

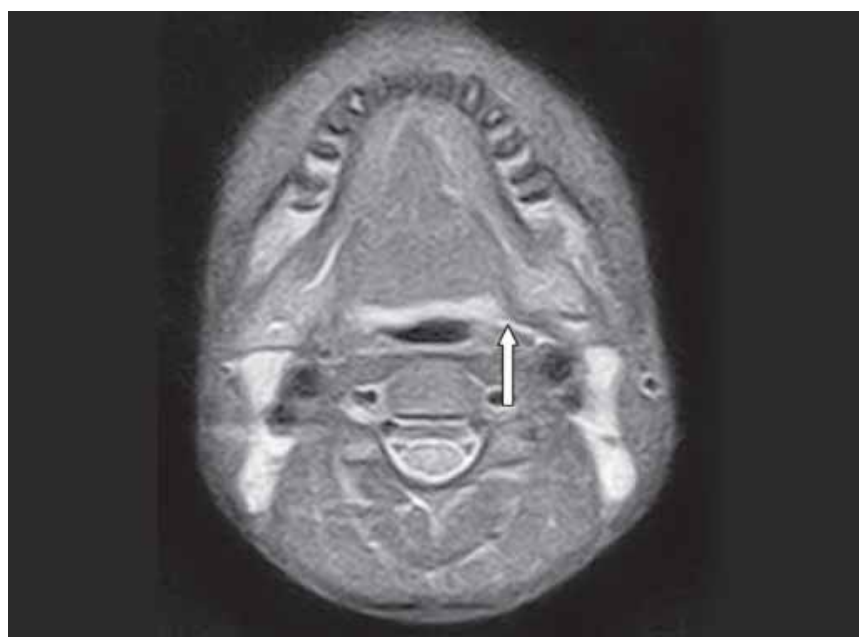

Fig. 3B: MRI of neck shows fistulous tract opening in left pyriform fossa 
tract was identified as firm cord-like structure, which was gradually dissected from the surrounding tissues. The tract was found to be running anteromedial to the carotid sheath, lateral to the upper pole of the thyroid gland and was extending till the pyriform sinus. A continuous intact fistulous tract of $7 \mathrm{~cm}$ length was excised (Fig. 4). Suturing was done in layers and pressure dressing was given.

Postoperative period was uneventful. Histopathological examination confirmed a linear tract lined by keratinized stratified squamous epithelium (Fig. 5). A t 4 weeks followup, patient was asymptomatic.

\section{DISCUSSION}

The branchial apparatus was first described by von B aer in 1827, whereas the anomalies in its development were credited by von A scheron. Branchial arches and their corresponding pouches develop from mesodermal condensations in the side wall of the embryonic pharynx. During embryonic development, the second arch grows caudally; envel op the third, fourth and sixth arches and form the cervical sinus by fusing with the skin caudal to these arches. The edges of cervical sinus fuse and the ectoderm within the fused tube disappears. M aldevelopment of the branchial apparatus leads to branchial anomalies that occur in the form of sinus, cyst and fistula. Persistence of ectoderm in the fused tube gives rise to branchial cyst. The branchial fistula results from the breakdown of the endoderm, usually in the second pouch. ${ }^{5}$

These anomalies may originate from the first to fourth cleft/pouch, with the commonest (95\%) arising from the second cleft/pouch. ${ }^{6}$ The third cleft may give rise to a fistula extending from the anterior border of sternocleidomastoid, passing superficial to the hypoglossal nerve, deep to the carotid arteries and piercing the thyrohyoid membrane to open into the pyriform fossa. ${ }^{7}$ The course of a third branchial fistula is derived from its embryological origin, in accordance with the branchial apparatus theory. A branchial fistula is thought to form when the mesenchyme that separates the cleft and pouch involutes, thus uniting them. Therefore, the fistula w ould be caudal to the structures from the following arch. A third branchial fistula would course between the third and fourth arch structures. ${ }^{6}$

K nowledge of the embryological development of branchial arches, their specific anatomical locations and their histological patterns can help in identifying a specific branchial arch lesion. B ranchial cleft remnants typically have their walls made up of stratified squamous epithelium with surrounding lymphoid tissue on histological examination. ${ }^{8}$ Although the knowledge of the theoretical tract is essential when planning for surgery, but the course of these fistulas is not al ways typical. ${ }^{6}$

In our patient, the branchial fistula was a complete fistula with internal opening in the pyriform sinus. The tract was found anteromedial to the carotid sheath and was not going deep to the carotid arteries as described in the literature. A neeza and $M$ azita et al reported in 2010, a complete third branchial fistula which was also anteromedial to the carotid sheath. ${ }^{6}$

Symptoms consist of intermittent or continuous discharge and recurrent attacks of inflammation following an attack of upper respiratory tract infection. The external opening may be seen to move upward with deglutition. ${ }^{9}$ For investigating the complete branchial fistula, barium contrast study or fistulogram can be performed which will clearly delineate the tract. In difficult cases both CT scan and M RI can be done.

Surgery is indicated to prevent the risk of recurrent infection and for cosmetic reasons. T reatment is complete surgical excision of the tract, in order to avoid its recurrence. Different methods for surgical excision of the tract have been used, the standard method includes stepladder excision for extensive fistulas. In our case, single incision around the external opening was sufficient to excise the tract completely. A nother method is stripping the tract using wire stilletes, vein strippers or arterial intimal strippers; however, being a blind procedure, it is not generally advocated if vital structures exist in the proximity. ${ }^{10}$ The recurrence rate of branchial anomaly is 3\% for a primary lesion and as high as $22 \%$ for lesions with previous infection and surgery. ${ }^{11}$ Complications of the surgery include secondary infection, injury to facial, hypoglossal, glossopharyngeal, spinal accessory nerves, injury to internal jugular vein, bad scar and hematoma formation. ${ }^{12}$

Endoscopic cauterization of the fourth branchial cleft sinus has been reported with effective result compared with open excision. ${ }^{13}$ Treatment by chemocauterization of the internal opening with trichloroacetic acid (TCA) has been reported with encouraging results. ${ }^{2,14}$

In 2009, Nixon and Healey reported the role of sclerotherapy for treatment of branchial sinus tract. They used 3\% sodium tetradecyl sulphate foam delivered via catheter along the length of the tract with significant improvement in the fluid discharge. ${ }^{15}$

In this article, we discussed a case of complete congenital third branchial fistula, which is rare in occurrence. The presence of a complete tract and its diagnosis by careful and complete history, physical examination and necessary investigations including fistulogram is very important for the complete treatment of the fistula.

\section{REFERENCES}

1. Clarke P. B enign neck disease: Infections and swellings. ScottB rown;s O torhinolaryngology Head and Neck Surgery (7th ed), Chapter 140, Great B ritain: Hodder A rnold; 2008;3:1779.

2. Jaka RC, Singh G. Complete congenital third branchial fistula on right side. O tolaryngology $\mathrm{Head}$ and Neck Surgery 2007;137:518-19. 
3. Bull PD. Branchial arch fistulae, thyroglossal duct anomalies and lymphangioma. Scott-B rown's Otorhinolaryngology, Head and Neck Surgery. Chapter 99. Great B ritain: Hodder A rnold (7th ed) 2008;2:1264.

4. Shekhar C, Kumar R, M ishra SK, Roy M, B havana K. The complete branchial fistula: A case report. Indian J of Otorhinolaryn and $\mathrm{Head}$ and $\mathrm{Neck}$ Surg. Oct-Dec 2005;57(4):320-22.

5. Chava A, Chakkyath J S. Complete branchial fistula. Bahrain M edical Bulletin Dec 2003;25(4).

6. A neeza WH, M azita A, M arina M B, Razif MY. Complete congenital third branchial fistula: Does the theoretical course apply? Singapore Med J 2010;51(7):e122.

7. Lee TC. Head and neck embryology. Scott-Brown's Otorhinolaryngology, Head and Neck surgery (7th ed), Chapter 65, Great B ritain: Hodder A rnold 2008;2:797.

8. Nayan S, M acLean J, Sommer D. Thymic cyst: A fourth branchial cleft anomaly. The Laryngoscope Jan 2010; 120(1):100-02.

9. Gangadhara S, A roor R, M unjunath D, R avishankar S. Complete fistula of the second branchial cleft: Report of a case with discussion on investigation and treatment aspects. The Internet J of Head and Neck Surg ${ }^{\mathrm{TM}}$ ISSN: 1937-819X, www.cancerar foundation.org, as accessed on 2/5/2011.

10. Lee STS, Krishnan MMS. Branchial fistula- a review. Singapore M ed J 1991;32:50-52.

11. Choi SS, Zalzal GH. B ranchial anomalies: A review of 52 cases. Laryngoscope 1995;105:909-13.

12. Francisco $C, A$ gaton $B$, et al. Diagnosis and treatment of branchial cleft cysts and fistulae. A retrospective study of 183 patients. International J of Oral and Maxillo Surg 1996;25:449-52.

13. Verret DJ, M cClay J, M urray A. Endoscopic cauterization of fourth branchial cleft sinus tracts. A rch O tolaryngol H ead N eck Surg 2004;130:465-68.

14. K im K H, Sung M W , et al. Pyriform sinus fistula: M anagement with chemocauterization of the internal opening. Ann Otol Rhinol Laryngol 2000;109:452-56.

15. Nixon PP, Healey AE. Treatment of a branchial sinus tract by sclerotherapy. Dentomaxillofacial Radiology 2011;40:130-32.

\section{Editorial Inputs}

\section{Complete Third Branchial Arch Fistula: A Rare Presentation (Multiple Surgery Failure)}

\section{Saurabh Varshney}

Professor and Head, Department of ENT, Himalayan Institute of Medical Sciences, Dehradun, Uttarakhand, India

The incomplete branchial fistula is not an uncommon congenital anomaly of branchial apparatus, but a complete one is rare. A nomalies arising from the third and fourth branchial cleft system rarely occur. Third and fourth branchial pouch fistulas are collectively referred to as pyriform sinus fistulas. B ranchial cl eft sinuses with external

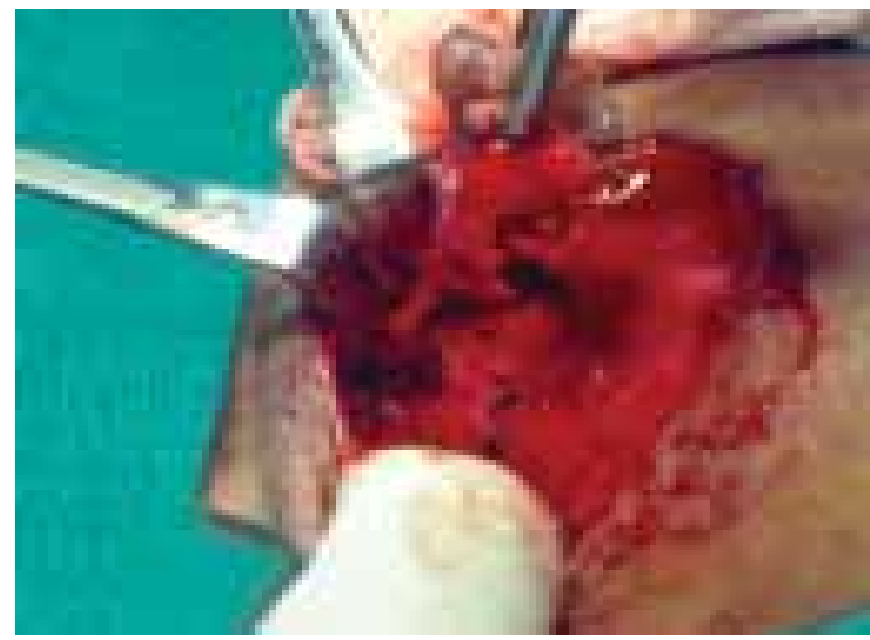

Fig. 1: Fistula tract dissected upto right sternocleidomastoid muscle openings are usually associated with the first and second branchial cleft arches, and those with internal openings are usually associated with the third and fourth arches. The course of a third branchial fistula is derived from its embryological origin, in accordance with the branchial apparatus theory.

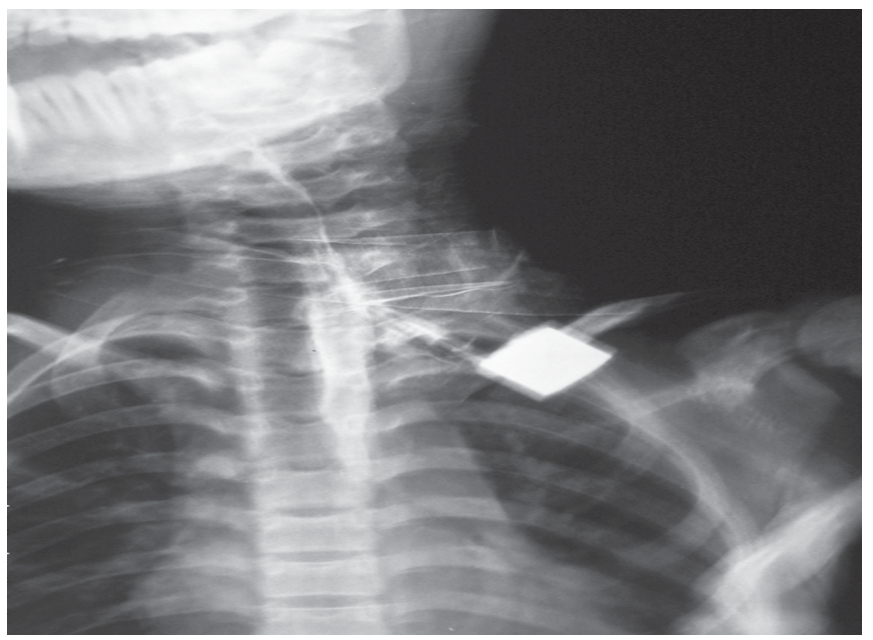

Fig. 2: Fistula tract passing through right sternocleidomastoid muscle 


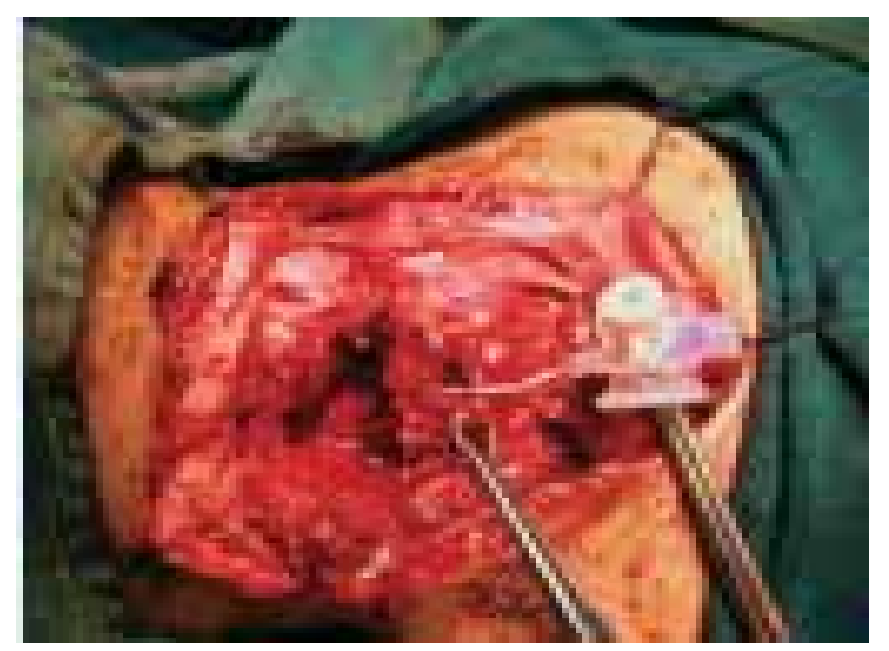

Fig. 3: Fistula tract passing through right thyroid

We have treated 3 such cases in last 5 years at our institute, the last case treated by us was a 15 -year-old male patient who presented with a history of a small opening with mucus discharge from the right side of the neck since birth, which increased on taking food. He had no family history of similar complaints. There was history of surgical excision of the fistula tract 9 times under general anesthesia without cure. Computed tomography with contrast injection into the external cervical opening revealed a patent tract from the neck skin to the base of the pyriform sinus, which was also confirmed by injecting methylene

\section{Editorial Inputs}

\section{Gauri Mankekar}

Branchial arch fistulas are easy to diagnose but difficult to treat. Often the tract vanishes between the carotid bifurcation

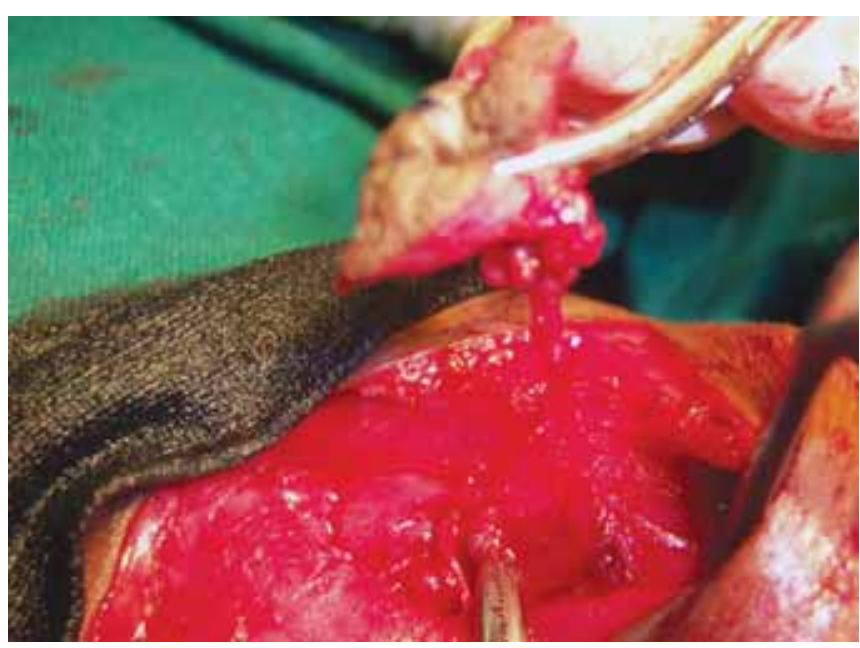

Fig. 4: Fistula tract defect in right priform sinus

blue from external opening and viewing it in right pyriform sinus with laryngeal endoscope. Complete excision of the tract up to the pyriform sinus with right hemithyroidectomy and closure of defect in right pyriform sinus was performed. Follow-up at 6 months has no recurrence. Our case with multiple surgery failures emphasizes that treatment of this condition requires complete removal of the tract in order to avoid recurrence; however, this can pose a risk to the surrounding structures, hence many surgeons perform incomplete excision of tract resulting in recurrence. and one cannot trace its entire length. Patients often undergo multiple surgeries before they arefree of the discharging fistula. 